\title{
PROCESSING SCIENCE: AN APPROACH FOR PREPREG COMPOSITE SYSTEMS
}

\author{
J.C. Halpin
}

Aeronautical Systems Division, Engineering, Wright-Patterson AFB OH 45433, USA and Materials Research Laboratory, Dept of Chemical Engrg, Washington University, St Louis MO 63130, USA

\section{J.L. Kardos and M.P. Dudukovic'}

Materials Research Laboratory, Dept of Chemical Engineering, Washington University, St Louis $M 1063130$, USA

\begin{abstract}
Processing science is an effort to provide integrated analysis of the life cycle of prepreg composite material systems in terms of fundamental chemical and transport processes. Models are developed to describe the prepreg from impregnation through curing. This integrated analysis procedure provides a basis for trades/optimization between resin chemistry, factory operations and curing procedures.
\end{abstract}

\section{INTRODUCTION}

The role of polymer technology in structural engineering applications has expanded from the pneumatic tire, through solid rocket motors, structural adhesives, and fiberglasspolyester or epoxy systems into the current use of graphite-epoxy systems in fixed and rotary-wing aircraft. During this evolution polymer technology has transitioned into applications requiring high confidence in its producibility and structural integrity (Ref 1$)$. These requirements are to be fulfilled in an industrial base which is traditionally non-chemical/polymeric in technical culture. This transition is also complex from a polymer science perspective. Polymer technology has moved from modifying fully polymerized systems (for example: elastomers which are masticated and vulcanized) into reactive pre-polymer systems (for example: capted polybutadines, adhesive films and pastes) and prepreg systems (for example: reinforcing fiber-epoxy or polyester). The modern concept of a prepreg began in the 1950 s with the Minnesota Mining and Manufacturing material system called "scotchply." In this material form a unidirectional or woven fiber system is coated with a partially reacted thermosetting system (polymer, cross-linking agent and catalyst). Prepreg is then provided to an engineering firm which is then responsible for its conversion into a solid structural form. In effect the traditional engineering organizations are now tasked to manage and bptimize a set of chemical processes, a manufacturing facility, and a structural form. This evolution has occurred at a time when polymer science and engineering has shifted its emphasis from thermosetting systems (1920s through the 1940s) to thermoplastic systems (1950s to the 1980s). The objective of this communication is to outline the technology base pertinent to the material systems, their associated processes, the interaction of these systems with the work procedures and environment in the manufacturing facilities, and the resulting characteristics of the cured systems which define their structural and thermomechanical limitations.

In pursuing this ambitious goal, the pertinent topics will be addressed in terms of the fundamental unit processes which provide the technical description of the material system. The format of the discussion will proceed as outlined in Figure 1. This format was selected to provide the basis of an integrated analysis; a systems approach for understanding the life cycle issues. The discussion will be specific and focused at simple traditional polymer science/chemical engineering transport concepts as a method to illustrate an intearated processing science methodology. 
IMPROVED MATERIALS/PROCESSES ETC.

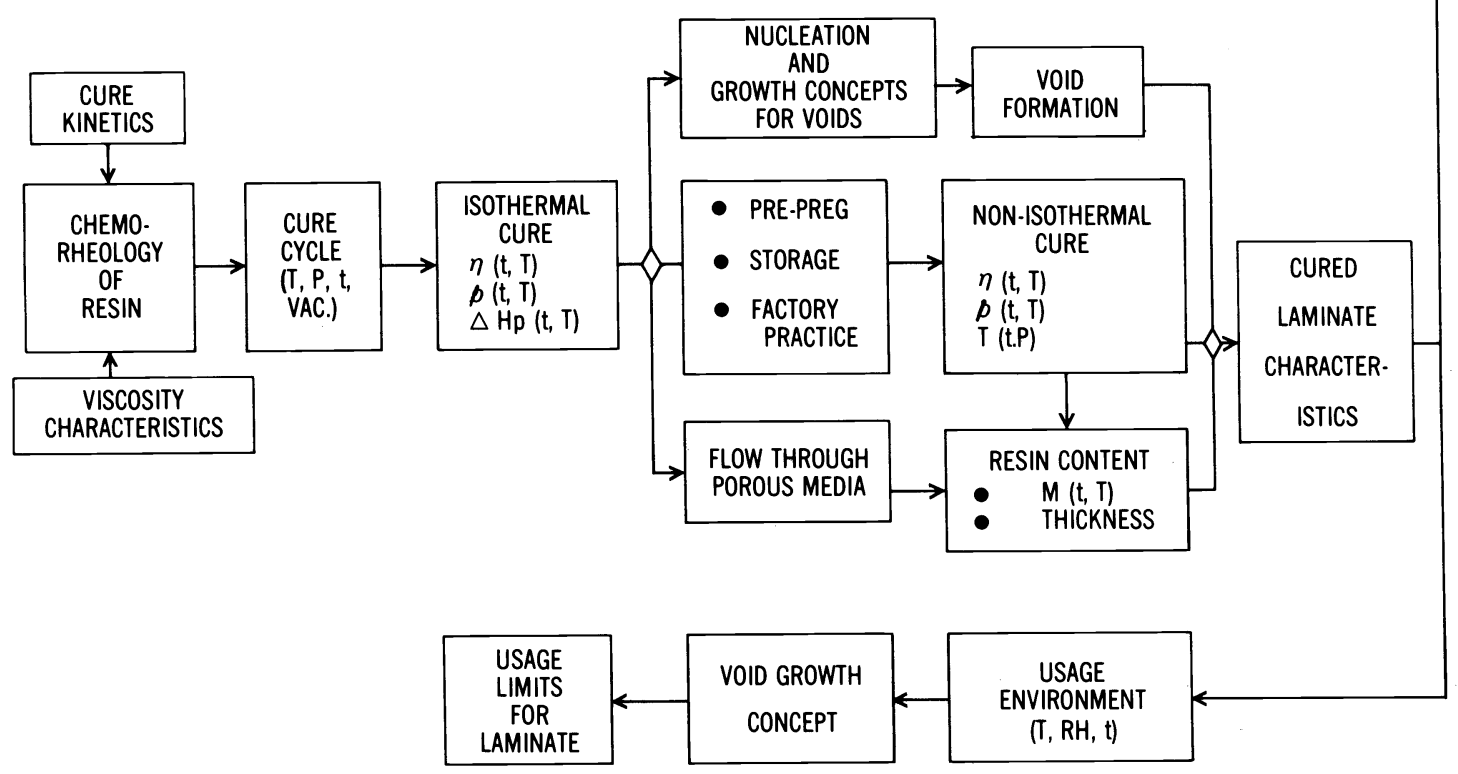

Fig. 1. Fundamental Processes Describe A Material System

\author{
ISOTHERMAL CHEMO-RHEOLOGY
}

Typical prepreg systems consist of fibers coated with 32 to 42 weight per cent epoxy resin, which after cure results in 26 to 30 weight per cent resin. A typical resin system (Ref 2 \& 3) will include tetraglycedyl 4,4' diamino diphenyl methane (TGDDM, Ciba-Geigy MY 720), and polyglycidl ether of Bisphenol A-Novalac (Celaness SU-8) cured with 4,4' diamino diphenyl sulfur (DDS, Ciba-Geigy Eporal). Typical formulations, Narmco 5208, consist of 60 to 65 weight per cent of TGDDM, about 20 weight per cent of DDS, and the remaining in SU-8, other polymers and possibly some fillers. These systems sometimes contain known complexes as catalysts (Ref 4). The reaction mechanism/kinetics involve (Ref $5 \& 6$ ) both a primary and secondary epoxy/amine addition reaction, as well as homopolymerizations. These reactions, while complex appear to be pseudo first order with a total heat of reaction, $\Delta H p$, on the role of 130 to 140 calories per gram of material. The heat of reaction, $\Delta H p$, reflects the combined contribution (Ref $7 \& 8$ ) of 270 calories per gram of resin for the primary amine addition, 170 calories per gram for the homopolymerization (hydroxyl-epoxide) reaction as well as the other reactions. The principal recantants have an average functionality of four.

The curing mechanisms of epoxy based matrices are being investigated by measuring changes in viscosity, spectroscopy as IR (infrared) and FT-IR (Fourier transfer infrared), calorimetric techniques as DSC (differential scanning calorimetry) and analytic measurements as HPLC (high pressure liquid chromatography) and GPC (gell permeation chromatography). These studies indicated that two reactions dominate the curing process of TGDDM-DDS systems. The initial reaction involves an epoxide ring opening following electrophilic attack by primary amine to form an amino alcohol. The second reaction, which has much lower rate constant than the ring opening by primary amine, is the etherification reaction between the epoxide and hydroxyl group. Secondary amine addition, which has been recognized to be the predominant reaction in other epoxy systems cured with linear amines, is probably hindered by the presence of the aromatic ring of the DDS.

The polymerization (curing) mechanisms of epoxy based systems can be modeled as pseudo first order reactions

$$
-\frac{d c}{d t}=k(T)[C]
$$

in which $\mathrm{C}$ is the concentration of epoxide groups and $\mathrm{k}$ is the apparent reaction rate in reciprocal time units. Following Flory (Ref 9 ) the extent of reaction for the epoxide groups, $p$, is given as

$$
p \simeq 1-e^{-k(T) t}
$$


where the rate constant at temperature $T\left({ }^{\circ} \mathrm{K}\right)$ is

$$
k(T)=a_{k} k\left(T_{0}\right)
$$

and

$$
\ln a_{k}=\frac{\Delta E}{R}\left(\frac{1}{T}-\frac{1}{T O}\right)
$$

Typical numerical values for the TGDDM-DDS based system are $k\left(120^{\circ} \mathrm{C}\right) 8.1 \times 10^{-4}(\min )^{-1}$ with a $\triangle E / R$ of 8700 for $N-5208$. For the mode] system of TGDDM-DDS illustrated in Fig 1 , the rate constant was approximately 0.01 (min) $)^{-1}$.

The step reaction polymerization of polyfunctional units (reactions with more than two functional groups, $f$, per molecule) leads to three dimensional polymers (Ref 9 \& 10). As polymerization proceeds, an infinitely large polymer network forms in the reacting mixture at an extent of reactions called the "gell-point."

$$
p_{c} \simeq \frac{1}{1-f} \simeq 0.33
$$

For the TGDDM-DDS systems the average functionality is about four. The time required to reach gel at a specific temperature is only a function of the reaction rate defined in Equations (2), (3), and (4).

$$
t_{c} \simeq \frac{1}{k(T)} \ln \left(1-p_{c}\right)^{-1} \simeq \frac{0.405}{0.01} \simeq 40.5 \min (F i g .2)
$$

As the polymerization proceeds to the gell-point the reaction mixture rapidly transitions from a low viscosity to a high viscosity system and then into an elastic/solid gell structure. As gelation is approached the weight average molecular approaches infinity and is the primary cause of rapid rise in viscosity. Let us illustrate this point for the epoxy system by assuming the reacting mixture is: (a) comprised of reactions having on the average of at least four functional groups per molecule of similar reactivity, and (b) a stoichiometric mixture (equal number of reacting molecule TGDDII-DDS, etc).

The progressive change in the molecular constitution sizes as the polymerization proceeds is given as

$$
w_{x} \cong\left[\frac{(f x-x)}{(x-1) !(f x-2 x+2)]}\right] p^{x-1}(1-p)^{f x-2 x+2}
$$

where $x$ is the number of units in the polymerizing molecule. The amount of nonomer TGDDM $(X=1)$ must continuously decrease:

$$
W_{1} \equiv(1-p)^{f} \simeq(1-p)^{4}
$$

which from Equation 2

$$
\simeq\left(c^{-k(T) t}\right)^{4}
$$

the dimmer TGDDM-DDS $(x=2)$ begins to format once:

$$
H_{2}=f P(1-P)^{2 f-2} 4 P(1-P)^{6}
$$
reaches a maximum amount near $P=0.15$ and then decreases; Fig 2 . Trimer formation
DDS-TGDDM-DDS $(X=3)$

$$
H_{3}=18 P^{2}(1-P)^{8}
$$

does not set in at once, delayed because dimmer must form first, and therefore maximizes later. These classical expectations were verified (Ref 8) for a TGDDM-DDS (35PHR) resin reaction at $177^{\circ} \mathrm{C}$ utilizing high pressure liquid chromatography, HPLC, to separate the constituents at different stages of the polymerization process.

The weight average, $\bar{x}_{w}$, number of units per molecule is found by summing over Equation (6)

$$
x_{w}=\sum x_{x}=\frac{1+p}{1-(f-1)-p}
$$

which may be rewritten, with Equation (4)

$$
\overline{x_{w}}=\frac{1+p_{p}}{1-\left(p / p_{c}\right)}
$$

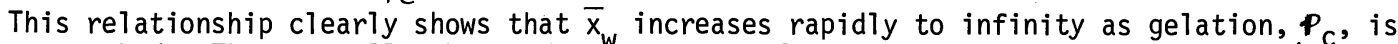
approached. The generally observed progression of the melt viscosity to infinity (Ref 11 \& 12) as the gell-point is approached, is a reflection of the dependency of the melt viscosity on the weight average molecular weight (Ref 13,14 \& 15).

$$
\eta=K(T)\left(x_{w}\right)^{a} \simeq 0.011\left(x_{w}^{-}\right)^{1.42}(\text { Fig. 2) }
$$



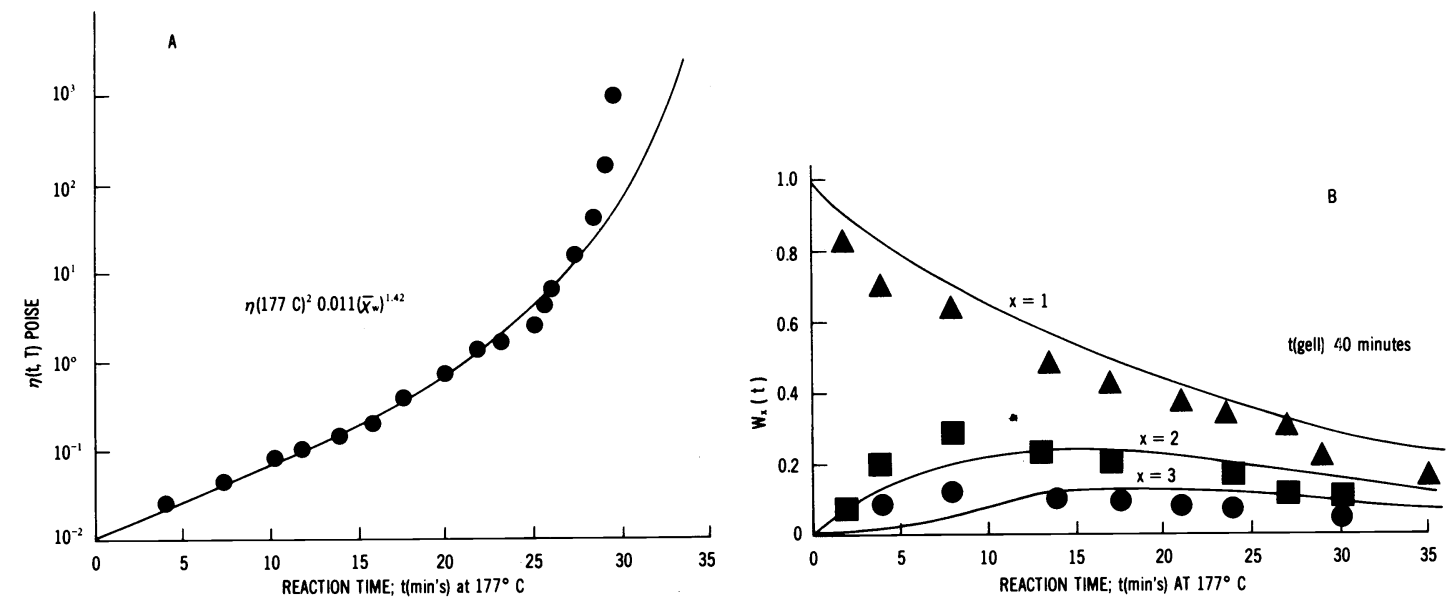

Fig 2. Dependence of resin viscosity and the weight fractions of molecular sizes on time during the polymerization of a TGDDM-DDS system at $177^{\circ} \mathrm{C}$.

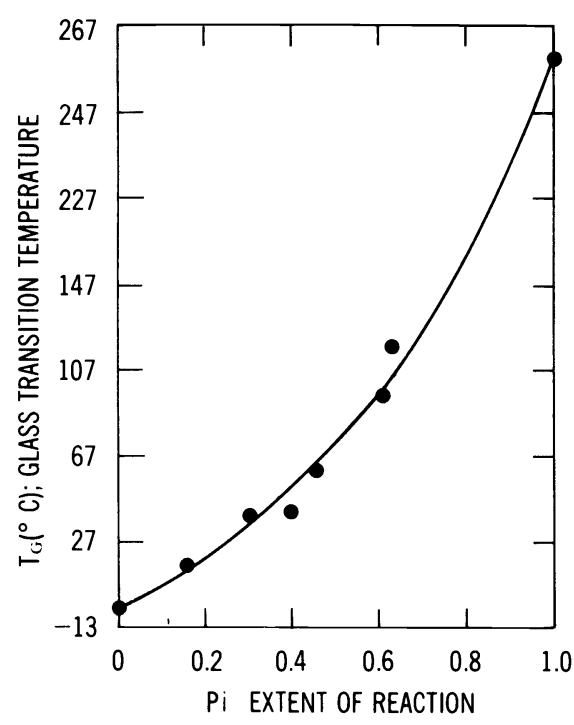

A.
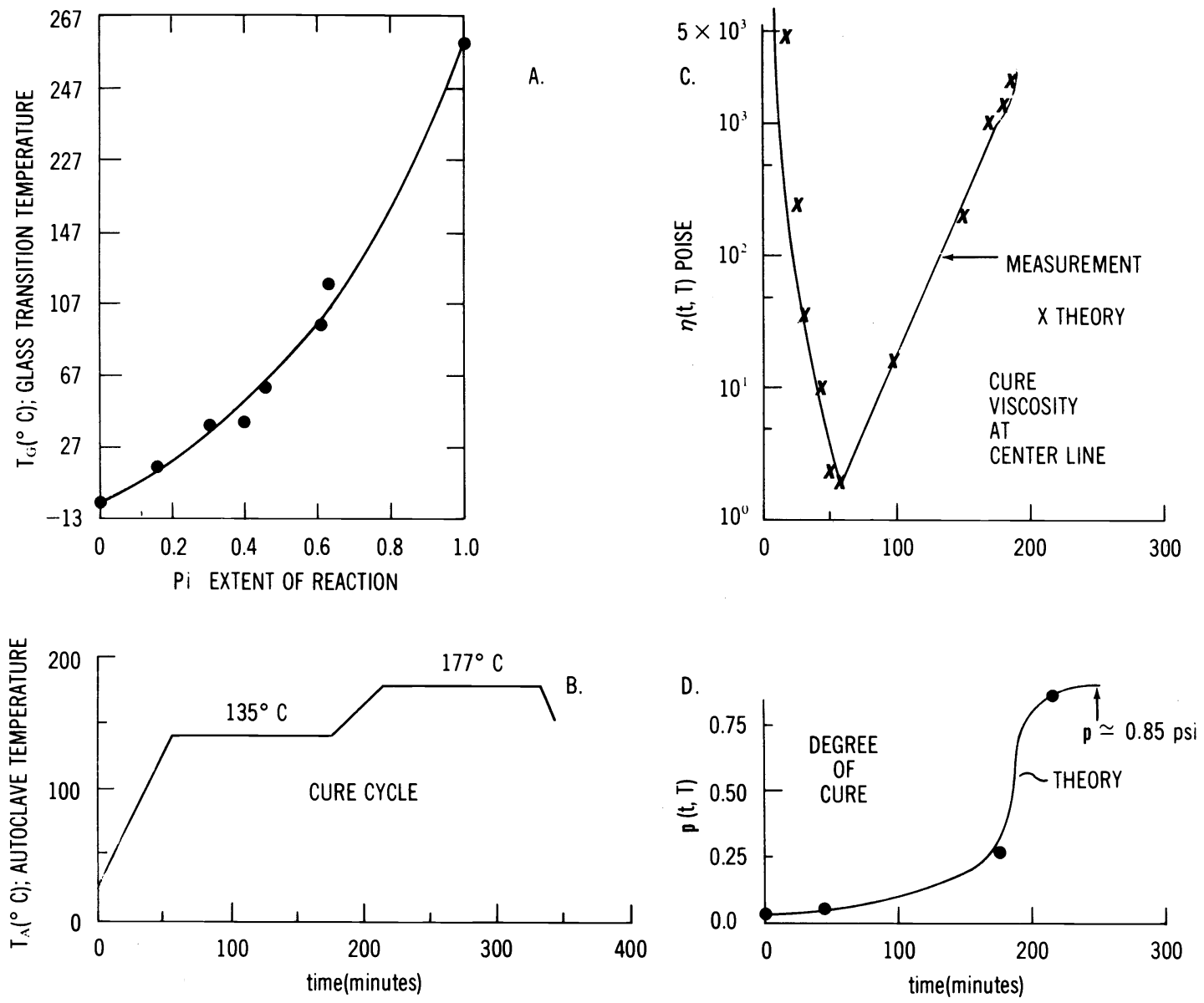

Fig 3. The dependence of glass-transition temperature on the degree of polymerization and the degree of polymerization and viscosity on time for the indicated time-temperature cure cycle. The material is Narmco 5208 a TGDDM-DDS system. 
Where $K$ is a temperature dependent constant, with the exponent " $a$ " and $K$ are constant reflection polymer characteristics. The temperature dependence of $K$ is defined as

$$
K(T)=a_{T} K\left(T_{0}\right)
$$

where (Ref 15 \& 16)

$$
\ln a_{T} \cong \frac{52(T-T g)}{40+(T-T g)}
$$

For the case where Equation (8) is fitted against experimental data at $T_{f}$ and then a test or prediction is desired at $T$, Equation (9) becomes

$$
K(T)=\Delta a_{T}\left(K\left(T_{f}\right)\right.
$$

and Equation (10) becomes

$$
\ln \Delta a_{T}=\frac{52\left(T_{f}-T g\right)}{40+\left(T_{f}-T g\right)}-\frac{52(T-T g)}{40+(T-T g)}
$$

In the Equations (10) and (10)' the temperature $\mathrm{T}$ is in degrees Kelvin and Tg represents the glass transition temperature for the polymer system.

The dependence of the temperature shift parameter a or $\Delta \mathrm{a}_{\mathrm{T}}$ in Equations (10) or (10)' are a function of the extent of reaction, $p$, and therefore of time, through Equation (2). The physical chemistry for the dependence of $\mathrm{Tg}(P)$ on the degree of reaction is outlined by Bueche (Ref 15) and can be approximated by

where

$$
\frac{1}{\operatorname{Tg}(p)} \simeq \frac{1-p}{\operatorname{Tg}(0)}+\frac{p}{\operatorname{Tg}(1.0)}
$$

$$
\text { and } \begin{aligned}
\operatorname{Tg}(0) & =\operatorname{Tg} \text { of reactant mixture at } p=0.0 \\
\operatorname{Tg}(1) & =\operatorname{Tg} \text { at } p=1.0
\end{aligned}
$$

For the N-5208 TGDDM-DDS systems Equation (11) becomes

$$
\frac{1}{\operatorname{Tg}(p)} \simeq \frac{1-p}{263}+\frac{p}{520}
$$

where $\mathrm{Tg}(\mathrm{p})$ is in $\left({ }^{\circ} \mathrm{K}\right)$. This relationship is illustrated in $\mathrm{Fig} 3 . \mathrm{a}$ and represents the lower bound for a reaction mixture which contains a blend of molecular weights, Equation (6). The data is that of Kaelble (Ref 17) who has also emphasized the correlation of thermosetting systems with traditional elastomeric technology. There has been ample criticism over the years regarding the inherent assumption in the gelation kinetics but the cumulative experience is that where these issues (Ref $9 \& 10$ ) have a modest impact on the numerical agreement between theory and experiment but not upon the overall considerations of the theory. The more recent work of C.W. Macosko (Ref 18) confirms this experience. The reason other workers (Ref 12 \& 19) have not treated their data in the manner presented here resides in the lack of recognition of the strong influence of $\mathrm{Tg}(\mathrm{p})$ in Equation (11) on the melt viscosity. Two factors dominate melt viscosity: $\bar{x}_{w}$ and $\mathrm{Tg}(p)$. The mode of presentation here permits a linkage between observable molecular entities, which can be monitored with available analytical techniques, and viscosity/reaction rate models which are the heart of a process science concept for heating systems.

A final consequence of the dependency of the glass temperature, $(\mathrm{Tg}(\mathrm{p})$, as the extent of reaction is that when $\mathrm{Tg}(\mathrm{p})$ approaches the polymerization temperature $\mathrm{T}$, the reaction mixture vitrifies and the polymerization process slows to near termination. This second effect of $\mathrm{Tg}(\mathrm{p})$ is accounted for in modification of Equation (2)

$$
P(t) \simeq\left[1-e^{-k(T) t}\right] e^{-\left(\frac{B}{T-T g(p)}\right)^{b}}
$$

where $B$ and $b$ are material constants and have approximate values of $B$ of $30^{\circ} \mathrm{K}$ and $\mathrm{b}$ of 4 for the epoxy system under consideration. In effect Equation (2)' limits $p(t)$ to $p(t)$ at $\mathrm{T}=\mathrm{Tg}(\mathrm{p})$ from Equation (11). 


\section{LIFE CYCLE INFLUENCES}

The life cycle of a prepreg system involves four basic segments: (1) the prepreg operation in which the fiber systems are hot melt or solvent impregnated with the compounded resin; (2) cooling the material to $0^{\circ} \mathrm{C}$ for storage at the prepreging facility, shipping to the manufacturer, and storage at the manufacturing facility; (3) thawing of the material and

"laying up" the prepreg plies to form a laminated on a molding tool and preparation for autoclave curing (covering the laminate with successive layers of glass bleeder fabric, Mylar or Teflon sheets and a vacuum bag), Fig 4 ; (4) the actual curing process which is generally an autoclave/vacuum degass process occurring on the tool inside the autoclave with the temperature, vacuum and pressure varied as shown in Fig 3 \& 4 . A typical life cycle history is:

(1) prepreging (hot melt coating)

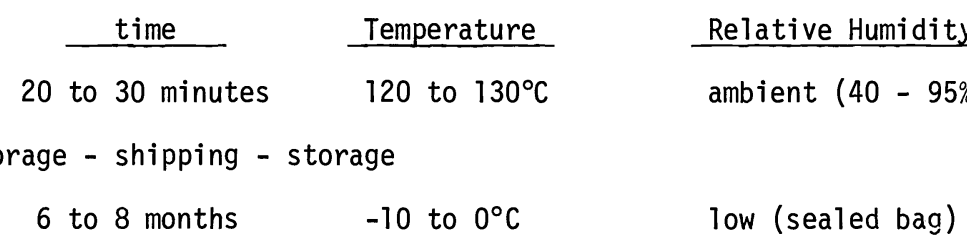

(3) thaw and factory work

$$
5 \text { to } 30 \text { days } \quad 15 \text { to } 30^{\circ} \mathrm{C} \quad \text { (30 to } 95 \% \text { ) }
$$

(4) autoclave cure

$$
400 \text { minutes } \quad 15 \text { to } 177^{\circ} \mathrm{C} \quad \text { vacuum out-gassing }
$$

Wote that the life cycle involves mass transfer of moisture between the prepreg system and the working environment as well as a time-temperature history.

The computation procedure for tracking these effects is to break down the history in differential time-temperature-humidity elements and sum through the life cycle. For tracking the extent of reaction, $p(t, T)$, the procedure is: from Equations $(1),(2)$, and (3), the extent of reaction at time $t_{1}$ is:

and at time $t_{2}$ is:

$$
\ln (1-p(1))^{-1}=k t_{1}
$$

$$
\ln (1-p(2))^{-1}=k t_{2}
$$

The incremental change $\Delta p$ is in going from $t_{1}$ to $t_{2}$ is

$$
\ln (1-P(2))^{-1}-\ln (1-p(1))^{-1}=k\left(t_{2}-t_{1}\right)
$$

and the combined effect of $t_{1}$ and $t_{2}$ is

$$
P(2)=1-(1-P(1)) e^{-k\left(t_{2}-t_{1}\right)}
$$

This equation can be generalized for the life cycle history

$$
P(t)=\sum_{n \simeq 0}^{i} 1-\left[1-P\left(t_{n-1}\right)\right] e^{-k(T)\left(t_{n}-t_{n-1}\right)}
$$

where the rate constant $k(T)$ is a function of time through the time-temperature life cycle. A typical extent of reaction history for Narmo 5208 is:

(1) after prepreging, $p \simeq 0.04$;

(2) after storage - shipping - storage, $p \simeq 0.06$ to 0.08 ;

(3) after factory lay up, $p \simeq 0.08$ to 0.12 ; and

(4) during the cure cycle, see Fig 3 ,

$$
\begin{array}{ll}
\text { beginning of } 135^{\circ} \mathrm{C} \text { hold } & p \simeq 0.1 \text { to } 0.13 \\
\text { end of } 135^{\circ} \mathrm{C} \text { hold } & p \simeq 0.25 \text { to } 0.28 \\
\text { beginning of } 177^{\circ} \mathrm{C} \text { hold } & p \simeq 0.35 \text { to } 0.37 \\
\text { during } 177^{\circ} \mathrm{C} \text { hold } & p \rightarrow 0.080 \text { to } 0.85
\end{array}
$$

The corresponding viscosity history is also illustrated in Fig 3 : the curve is a direct measurement and the $x$ 's are the computed values. Note that at the beginning of factory 
lay up the glass temperature of the prepreg is about 2 to $5^{\circ} \mathrm{C}$ and at the completion of : the typical lay up it could be as high as 8 to $10^{\circ} \mathrm{C}$. At a glass temperature the material is approaching a "boardy" condition ( $\mathrm{Tg} \rightarrow \mathrm{RT}$ ) with a loss of apparent "tuck", Ref 17 . Also note that the material "gells" $(p>0.33)$ in transit from the $135^{\circ} \mathrm{C}$ to the $177^{\circ} \mathrm{C}$ temperature hold and that polymerization terminates at $p \sim 0.85(\mathrm{Tg}(p) \rightarrow T$ (cure)). These calculations were developed for an "optimized cure schedule," Fig 3, based upon the assumption that the centerlining temperature of the part was within $5^{\circ} \mathrm{C}$ of the programmed autoclave temperature.

NON-ISOTHERMAL CURE

The general case of curing processes includes the recognition that all important thermosetting reactions are exothermic and involve material systems with low thermal conductivities. The reacting system must be viewed as a non-isothermal bulk reactor with volumetric heat generation and areal heat transfer for the initial heating and for the disipation of the heat of reaction. The objective in the development of a material system processing cycle is to minimize the potentially large temperature excursions induced through the internal heat generation during curing or the thermal lag in the heat up or cool down segments of the process cycle. The general approach to the treatment of heat transfer in polymer reactions is through the conservation of energy equation (Ref 20 thru 26)

$$
\rho C_{p} \frac{\partial T}{\partial t}=\frac{\partial}{\partial x}\left(k_{T} \frac{\partial T}{\partial x}\right)+H_{R}^{\prime}
$$

which has been reduced to a slab format. The parameters are: $\rho$, the density; $C_{p}$, the heat capacity and $k_{T}$, the thermal conductivity in the direction perpendicular to the slab; and $H_{R}^{\prime}$, the rate of internal heat generation expressed on a unit volume basis. Equation (13) simply states that the rate of change of energy in a small volume element will equal: (a) the rate of energy transfer into or out of that volume element; plus the rate of energy liberation (or absorbed) in that volume element due to a chemical reaction. $H_{R}^{\prime}$, the volumetric rate of heat generation $\left(\mathrm{cal} / \mathrm{cm}^{3} \mathrm{sec}\right)$ by a chemical reaction is:

$$
H_{R}^{\prime}=\rho \Delta H_{R} \bar{w}_{p}\left(k e^{-k t}\right)
$$

where $\rho$ is the density of the composite; $\Delta \mathrm{H}_{R}$ is the heat of polymerization; $\bar{w}_{p}$ is the weight fraction of polymer in the curing reaction, See Equation $(26)$, and the term $p\left(k_{e}-k t\right)$ is the rate of change of the degree of polymerization with time developed from Equations (1), (2), and (3) for first order kinetic reactions. Interestingly, the expression developed by Kamal and Coworkers (Ref 11) for other epoxy systems also approximate the heat of polymerization TGDDS-DDS based systems

$$
\Delta H_{p}(\mathrm{cal} / \mathrm{gm}) \simeq 0.6 \mathrm{~T}_{\mathrm{c}}-0.3 \times 10^{-3} \mathrm{~T}_{\mathrm{c}}^{2}-72
$$

where $T_{c}$, the cure temperature, is in $\left({ }^{\circ} \mathrm{K}\right)$. For a polymerization at $T_{c}=177^{\circ} \mathrm{C}$ the heat of reactions would be $138 \mathrm{cal} / \mathrm{gm}$ or $48 \mathrm{cal} / \mathrm{gm}$ of a prepreg with 35 weight per cent resin.

The cited literature (Ref 20 thru 26) address the numerical procedures required to compute the temperature inside the reacting mass as a function of position and time. However, our objective is to understand what conditions are required to avoid adiabatic/unsteady state reaction conditions. In this perspective, it is instructive to examine the critical material parameters associated with Equation (13):

(a) The critical half thickness, $h_{c}$, for adiabaticlite curing (Ref 25) is:

$$
h_{c}=\sqrt{\frac{\text { heat conduction rate }}{\text { chemical reaction rate }}}=\sqrt{\frac{\alpha}{k}}
$$

where $\alpha$ is the thermal diffusivity $\left(k_{T} / \rho C_{p}\right)$.

(b) The apparent rate of adiabatic induced temperature change $(d T / d t)_{A}$ :

$$
(d T / d t)_{A}=\frac{\Delta H_{R} \bar{w}_{p}\left(k e^{-k t}\right)}{c_{p}}
$$

and

(c) The potential adiabatic temperature rise, $\Delta T_{A}$ :

$$
\Delta \mathrm{T}_{\mathrm{A}}=\mathrm{T}_{\mathrm{A}}-\mathrm{T}_{\mathrm{C}}=\frac{h^{2} \Delta \mathrm{H}_{R} \omega_{p}\left(k e^{-k t}\right)}{2 k_{T}}
$$

For typical material having the characteristics of $\mathrm{N}-5208$ with graphite fibers these terms (Equations (15) - (17)) would be 


\begin{tabular}{ccc}
$\mathrm{Tc}\left({ }^{\circ} \mathrm{C}\right)$ & $\frac{\left.h_{\mathrm{C}}(\mathrm{cm}) \text { (Notal } \mathrm{plies}\right)}{12.3(1700)}$ & $\frac{\mathrm{dT} / \mathrm{dt}\left({ }^{\circ} \mathrm{C} / \mathrm{sec}\right)}{120}$ \\
\cline { 2 - 3 } 135 & $8.3(1200)$ & $0.006^{\circ} \mathrm{C} / \mathrm{sec}$ \\
177 & $3.1(444)$ & $0.04{ }^{\circ} \mathrm{C} / \mathrm{sec}$
\end{tabular}

These results clearly show that current curing schedules, Fig 3, combined with prepreg resin content, $\bar{W}_{p}$, and slow reaction rates $k$ do moderate the exothermic tendencies of the subject epoxy systems up to about 400 ply thickness. It is also evident that the influence of modifying cure temperature/schedule, catalyst influences on the reaction rate; implications for the curing of "thick" parts, etc, are within the predictive capability of current technology. Finally, the results cited in Fig 3 are typical for the case when the curing slab is less than, $h_{c}$, of Equation (15).

\section{COMPACTION AND RESIN FLOW}

What goes on in a laminate as the temperature is increased and the autoclave pressure is applied is a complex process. As the temperature is increased, Fig 3, the resin viscosity decreases rapidly; reaches a minimum somewhere between 100 and $135^{\circ} \mathrm{C}$; and then begins to increase. At this point little laminate consolidation has occurred other than what is associated with wetting between plies. During the $135^{\circ} \mathrm{C}$ temperature hold, autoclave pressure is applied, Fig 4, and laminate consolidation occurs. The hydrostatic autoclave pressure does not act as a source of hydrostatic pressure to the resin. Autoclave pressure is transmitted to the laminate through the deflection of the vacuum bag responding to a pressure differential consisting of the internal bag vacuum, $\Delta P_{\psi}$, of about 0.9 atmospineres absolute pressure and the autoclave pressure, $P_{A}$, of about 5.8 atmospheres absolute pressure. This deflection of the vacuum bag is reacted by the fiber mass in the laminate which transfers the pressure load to the tool surface. This load transfer process involves a mass transfer process, the flow of the resin resisting the compaction of the fiber mass. In effect the resin will flow in response to the hydronic pressure generated in the fiber mass undergoing compression. Resin flow will react to pressure gradient from the tool surface, $\left(\Delta P_{V}+P_{A}\right)$ up to the pressure existing in the bleeder material, $P_{V}$, (approximately 0.1 atmospheres). AThe "bleeder" is simply a porous material for the absorption of resin "bleed" from the laminate. There will also be a similar pressure gradient from the center of the laminate out to the lateral edqes of the laminate or slab. FLOW MODEL

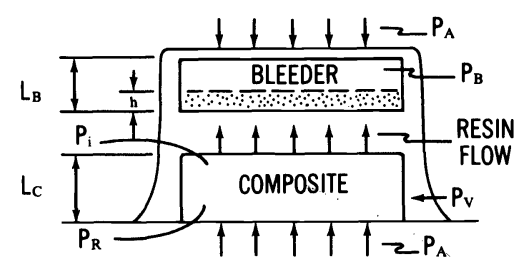

RESIN GRADIENTS

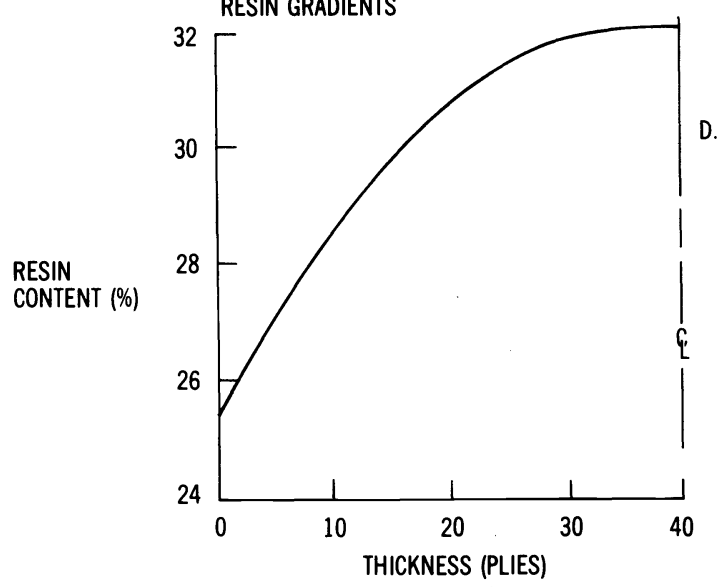

A.
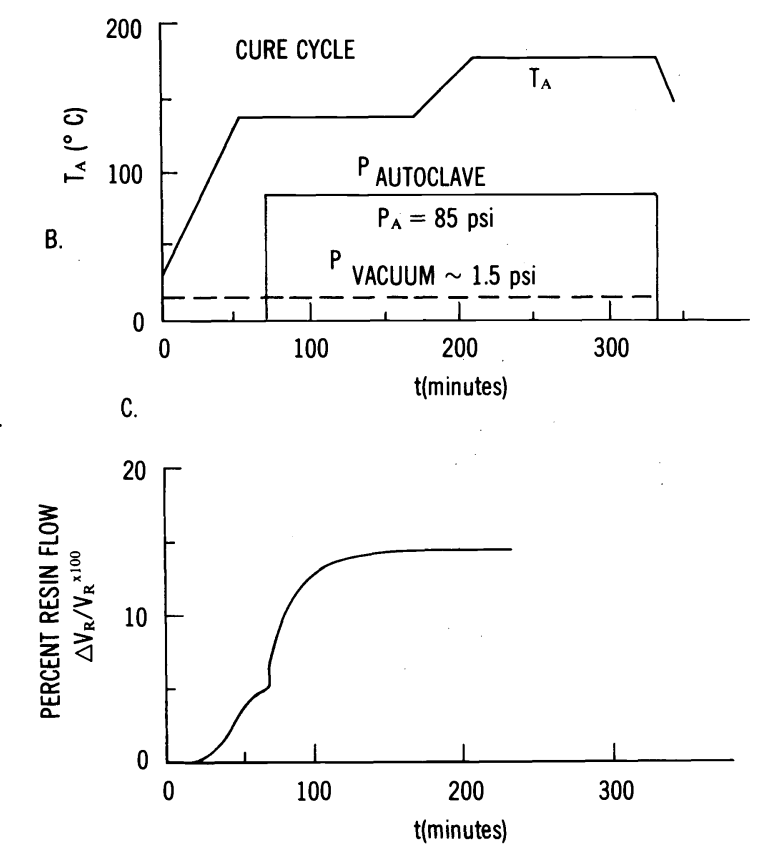

Fig 4. Vacuum bag/bleeder configuration and laminate consolidation. 
In effect, the laminate behaves as an elastic "sponge" permeated with a fluid. When the "sponge" is compressed some of the fluid will flow out reducing the fluid weight content in the sponge. This problem has been addressed by Gent and Rusch (Ref 27) and is centered around Darcy's Law. Darcy's Law for laminar flow of viscous liquids, (Ref 28 thru 31 ) states that the velocity, er, of fluid flow through a porous medium

$$
i \simeq \frac{K}{n} \frac{d P}{d x}
$$

is proportional to the pressure gradient $(d P / d x)$. The proportionality constant is the ratio of the permeability of the medium to the viscosity of the fluid. The volumetric flow rate will be

$$
Q \simeq A \cdot \frac{K(\Delta P)}{n \cdot h}
$$

where $A$ is the cross-sectional area normal to the flow path and $\Delta P$ is the pressure change along the flow vector or path of distance $h$. The total volumetric flow from the three edges of a slab will be

$$
Q_{T}=Q_{1}+Q_{2}+Q_{3}
$$

where the subscripts refer to the major plane surface, major edge and minor edge surfaces. Inserting Equation (19) into Equation (20)

$$
\text { or } \begin{aligned}
Q_{T} & =\left(\frac{A_{1} K_{1}}{h_{1}}\right) \frac{\Delta P}{n}+\left(\frac{A_{2} K_{2}}{h_{2}}\right) \frac{\Delta P}{n}+\left(\frac{A_{3} K_{3}}{h_{3}}\right) \frac{\Delta P}{n} \\
Q_{T} & =\left(\frac{A K}{h}\right)_{\text {eff }} \frac{\Delta P}{n}
\end{aligned}
$$

where the "effective" term means that the lateral area, permeability and path length are approximated as the weighted average of the contributions of $Q_{1}, Q_{2}$ and $Q_{3}$. The areas $A$ and $h$ are directly measurable quantities. Relative as well as absolute values of the permeability can be estimated by using a "tagged" resin or fluids and monitoring their flow through a cube or slab under compression induced flow. For unidirectional oriented prepregs the ratio of the permeability to flow in the plane parallel to the tool surface to the flow across the plies, the direction normal to the tool surface is

$$
\frac{k_{2}}{k_{1}} \sim \frac{k_{3}}{k_{1}} \sim 1 \text { to } 1.4 \times 10^{3} \text { with } k_{1} \sim 10^{-5} \mathrm{~cm}^{2}
$$

Typically the relative dimensions are $\frac{h_{2} \text { or } h_{3}}{h_{1}} \sim 10-10^{3}$ and $A_{1}=h_{2} h_{3}$;

$A_{2}=h_{1} h_{2}$, and $A_{3}=h_{1} h_{3}$. $h_{1}$ is vertical distance from the tool surface to the top of the laminate.' A typical ply of prepreg is about $0.0022-0.0028 \mathrm{~cm}$.

The authors have found that the consolidation of plies can be modeled as follows. The weight content of fibers after a period of consolidate, $W$, is

$$
W_{(t)}=F(W(\infty)-W(i))+W(i)
$$

where weight fractions of fibers $W_{N}=\bar{W} / W_{(*)}$ have been normalized to their maximum later packing; $W(*) \simeq 0.85$. The term $W(\infty)$ is the normalized weight fraction of fibers in the prepreg after compaction at a pressure $P$ (ATMs) relative to the pressure $P_{(*)}$ for maximum
compaction.

$$
W(\infty) \simeq a(P / P(*))^{b} \simeq 1.0(P / 8)^{0.1}
$$

These expressions are defined in the context that the major surface area, $A$, is nearly constant during compaction. The time dependent fractional change in fiber content during compaction is

$$
F=1-\exp -2.6\left\{\left(\frac{K}{h_{2}}\right) \cdot \frac{(\Delta P) t}{n_{(t, T)}}\right\}^{0.75}
$$

The fractional change in fiber concentration as both a function of time and position (conc in individual plies) can be expressed as

$$
\frac{w(t)-w(i)}{w(\infty)-w(i)} \equiv G=1-\sin \left(\frac{x}{h}\right) \exp -2.6\left\{\left(\frac{k}{h^{2}}\right) \text { eff } \frac{(\Delta P) t}{n(t, T)}\right\}^{0.75}
$$


The term $\Delta P$ is defined as the initiating compaction pressure: the pressure differential acting across the vacuum bag minus the vacuum pressure. The weight fraction resin will be given as

or

$$
\bar{W}_{p}(t)=1-W(t) W(*)
$$

$$
\bar{w}_{p}(t, x)=1-w(t, x) w(*)
$$

Figure $r$ illustrates the results of estimates of resin flow, Equations (22) - (24); and resin gradients, Equations (22), (23) and (26), for a N-5208 prepreg system cured as shown in the figure. To implement the solution, increments of $\Delta t / \Delta n(t, T)$ from Fig 3 were entered into either Equations (25) or (26). The resin gradient shown in Fig 4 impacts both dimensional and weight control of the cured object as well as shifting the elastic axis of the fabricated plate or bar.

\section{MOISTURE, PREPREGS AND VOID FORMATION}

At this point on our flow diagram, Fig 1, traditional computation procedures have been shown to account for resin advancement during prepreging and factory lay up, temperature, viscosity, degree of cure, and resin flow as a function of position and time during cure. While this is necessary, it is insufficient for it does not address what happened to absorbed moisture and volatiles during cure. Attendant to this is the question: What

is the quality of the laminate? To address this item let us return to the factory lay up process. After the prepreg is thawed it is rolled out, in single sheets, cut and layed up on the mold. During this lay up process the uncured resin absorbs moisture rapidly from both sides, coming into equilibrium with the factory environment. The moisture solubility, H. (wt \%) in fresh prepreg is:

$$
M(\infty) \simeq 5.58 \times 10^{-5}(\mathrm{RH})^{2}
$$

the diffusivity is:

$$
D \simeq 0.11 e^{-2817 / T}
$$

where $\mathrm{T}\left({ }^{\circ} \mathrm{K}\right)$ and $\mathrm{RH}$ in $(\%)$ are the respective factory temperature and relative humidity. The moisture content after a period of time, $t$, is

$$
M(t)=(M(\infty)-M(i))\left[1-\exp -2.58\left(D t / h^{2}\right)^{0.75}\right]+M(i)
$$

where $M(i)$ is the moisture content in the prepreg received from the prepreger and $h$ is half thickness of a ply or a laminate for two sided transfer. Although absorption for one ply is rapid as it is being layed up,very little moisture is lost from the stacked plies or laminate during the autoclave vacuum/temperature cycle. This results because the laminate rests on a tool surface and can only desorb from the upper surface. The thickness $h$ in Equation (27) is doubled. In addition, the total number of plies undergoing moisture transfer is 10,100 or 400 versus one individual ply. Simple calculations demonstrate that it would take from two hours for a ten ply, to more than a thousand hours for a 100 ply laminate to begin "drying" at the laminate center when exposed to $135^{\circ} \mathrm{C}$ and vacuum. The only conclusion is that superheated water vapor is available inside the curing laminate. Cavitation by superheated liquids (Ref 32) represents a general case of void formation which is frequently encountered in the forming and curing of polymers. The production of foamed plastics or elastomers represents a technology area in which cavitation is induced to achieve a controlled degree of cell size and porosity. More frequently, cavitation and void formation is an undesired consequence which for laminated solids provides the manufacturing flaws dominating the delamination fracture modes. That is the quality concern cited in Ref 1 .

The general criteria for cavitation in either a liquid or solid is well understood (Ref 32 , $33 \& 34$ ) and summarized as:

where

$$
\sigma(t)+P(\text { int })=\frac{1}{2} G(t) F_{1}(\lambda)+\frac{2 \gamma L V}{r^{*} \lambda}+P(\text { ext })
$$

$\sigma(t)$ is the external hydrostatic tension stress;

$P$ (int) is the internal vapor pressure within the cavity;

$G(t)$ is the time/temperature shear modulus of the solid, if appropriate;

$F,(\lambda)$ is a function of the extension ratio, $\lambda$, of the cavity surface;

$\frac{2 \gamma L V}{r^{*} \lambda}$ is the effect of surface tension for a critical bulk cavity of radius $r^{*}$;

and $\quad P(e x t)$ is the external pressure. For the case of uncured epoxy in contact with water vapor the liquid vapor surface tension, $\gamma \mathrm{LV}$, is about 50 dynes/cm; therefore the surface tension term of Equation (28) makes a trivial contribution when the cavities are 
about $10^{-2} \mathrm{~cm}$ in diameter. In addition Equation (20) reduces to

$$
P(\text { int })=P(\text { resin }) \simeq P(\text { ext })
$$

at equilibrium. In this expression $P$ (resin) is the hydraulic pressure in the resin phase during compaction, Fig 4, and previous sections. Equation (29) simply states that microcavities will expand under the influence of an internal pressure unless that pressure is balanced by a compressive pressure in the resin. In the general correlation by Kaeble (Ref 33), it was printed out that cavitation generally involved the growth of prenucleated cavities. We are then gestricting our interest to the growth conditions of pre-existing micro-cavities $\left(d<10^{-2} \mathrm{~cm}\right.$ at a concentration of about $\left(1\right.$ to $1.5 \times 10^{3}$ per $\left.\mathrm{cm}^{3}\right)$.

Void growth is then dependent upon the rate of internal pressure, $P$ (int), generated inside a cavity. $P($ int $)$ can increase when $C(\infty)$, the equilibrium concentration in the bulk resin, exceeds $C($ sat). C(sat) is the water concentration at the bubble resin interface in equilibrium with the vapor within the void.

Before proceeding further let us define three quantities:

(a) The dependence of the vapor pressure on temperature

$$
\mathrm{P}\left(\mathrm{H}_{2} \mathrm{O}\right)=4.96 \times 10^{5}-\frac{4892}{\mathrm{~T}}
$$

where $T$ is in $\left({ }^{\circ} \mathrm{K}\right)$

(b) The water concentration in the resin, $c()$, which can be obtained from the measured solubility data:

$$
\begin{aligned}
& C(\infty)\left(\frac{g m \mathrm{H}_{2} \mathrm{O}}{\text { cc resin }}\right)=\frac{M(\infty)}{100}\left(\frac{\text { gms } \mathrm{H}_{2} \mathrm{O}}{\text { gm prepreg }}\right) \times \frac{1}{0.32}\left(\frac{\mathrm{gm} \text { prepreg }}{\mathrm{gm} \text { resin }}\right) \times 1.22\left(\frac{\mathrm{gms} \text { resin }}{\mathrm{cc} \text { resin }}\right) \\
& C(\infty)=3.819 \times 10^{-2} M(\infty)=2.13 \times 10^{-2}\left(\frac{\mathrm{P}_{\mathrm{H}_{2} \mathrm{O}}}{\mathrm{P}_{\mathrm{H}_{2} \mathrm{O}}}\right)^{2} \\
& C(\infty)=2.13 \times 10^{-6}(\mathrm{RH})^{2} \text { or } \\
& C(\infty)=8.651 \times 10^{-14} \mathrm{e}^{\frac{9784}{\mathrm{~T}}} \mathrm{P}_{\mathrm{H}_{2} \mathrm{O}^{2}}
\end{aligned}
$$

c. At the bubble/void surface saturation occurs, $C($ sat), when the partia' pressure of the water equals the total internal pressure

$$
C(\text { sat })=8.651 \times 10^{-14} \text { e } \frac{9784}{T} p^{2} \text { (resin) }
$$

At each temperature, a pseudo steady state is established with respect to concentration profile between the resin bulk and the void surface. When $P$ (int) $>P($ resin). The diameter of a spherical bubble will grow by diffusion as described by Scriven, (Ref 35).

$$
d_{B}=4 B \sqrt{D t}
$$

The change in diameter per unit time (growth rate) is:

$$
\frac{d d_{B}}{d t}=\frac{2 B D}{\sqrt{D t}}=\frac{8 B^{2} D}{d_{B}}
$$

assuming that at $t=0 d_{B} \cong 0$ (1ess than $0.01 \mathrm{~cm}$ ). The terms:

$d_{B}$ is bubble diameter; $t$ is time $(\mathrm{hr}) ; D=$ diffusion coefficient $\left(\mathrm{cm}^{2} / \mathrm{hr}\right)$;

$B=$ constant given by the following equation; and

$$
\frac{C(\infty)-C(\text { sat })}{P_{g}}=2 B^{3} e^{3 B^{2}} \int_{B}^{\infty} x^{-2} e^{\left(-x^{2}-\frac{2 B^{3}}{x}\right)} d x
$$

where $\mathrm{Pg}_{\mathrm{g}}$ (gms/cc) is the water vapor density in the bubble.

As the void grows, the finite size of the void or bubble makes it desirable to utilize an approximate solution (Ref 36 ); 


$$
\begin{aligned}
& \left(\frac{\mathrm{d}_{B_{2}}}{\mathrm{~d}_{B_{1}}}\right)^{2}=1-\frac{N_{a}}{\sqrt{\pi}} x+\left(\frac{N_{a}}{3 \pi}-\frac{1}{4}\right) N_{a} x^{2}+\left(\frac{5}{12}-\frac{8}{5 \pi}+\frac{N_{a}}{18 \pi}\right) \frac{N_{a}^{2}}{\sqrt{\pi}} x^{3} \\
& N_{a}=\frac{C_{(s a t)}-C(\infty)}{\rho_{g}}=-B \\
& x=\frac{2 \sqrt{D t}}{R_{0}}=\frac{4 \sqrt{D t}}{d_{B}}
\end{aligned}
$$

The following table summarizes the expected void volume changes (Equations (29) thru (37) for the conditions in which fresh prepregs were conditioned to a moderate and a larger factory humidity environment $C(\infty)$ and then cured in accordance with the cure schedule of Fig 4 . The

\begin{tabular}{|c|c|c|c|c|c|}
\hline $\begin{array}{l}\text { Cure Cycle } \\
\text { time (hrs) }\end{array}$ & $\begin{array}{l}\text { Cure } \\
\text { Temp }\left({ }^{\circ} \mathrm{C}\right)\end{array}$ & $\begin{array}{l}\text { Vacuum } \\
\text { (ATMS) }\end{array}$ & $\begin{array}{l}\text { Autoclave } \\
\text { Pressure } \\
\text { (ATMS) } \\
\end{array}$ & $\begin{array}{l}\begin{array}{l}\text { Bubble } \\
\text { for } C(\infty)\end{array} \\
0.0053 \mathrm{gm} / \mathrm{cm} \\
\end{array}$ & $\begin{array}{l}\text { Diameters }(\mathrm{cm}) \\
\text { of } \\
0.021(\mathrm{gm} / \mathrm{cm}) \\
\end{array}$ \\
\hline 0 & 25 & 0.1 & 0 & 0.01 & 0.01 \\
\hline 0.16 & 44 & 0.1 & 0 & .01 & initiated \\
\hline 0.29 & 62 & 0.1 & 0 & initiated & \\
\hline 0.92 & 135 & 0.1 & 0 & 2.02 & \\
\hline 1.17 & 135 & 0.1 & 0 & 2.66 & 11.07 \\
\hline 1.18 & 135 & 0.1 & 5.78 & 0.38 & 2.86 \\
\hline 2.92 & 135 & 0.1 & 5.78 & 0.25 & 2.60 \\
\hline 3.23 & 158 & 0.1 & 5.78 & 0.25 & reinitiated \\
\hline 3.59 & 350 & 0.1 & 5.78 & & \\
\hline 5.59 & 350 & 0.1 & 5.78 & Case 1 & Case 2 \\
\hline
\end{tabular}
following data are typical for a slab of 100 to $400 \mathrm{plies}$ in thickness with large lateral dimensions.

An examination of this table shows the temperature-time condition in which sufficient internal pressure is generated to initiate bubble growth for Case 1 and 2; the large size these bubbles can obtain if transport to a surface does not occur; and their compression when autoclave pressure is applied. Case 1 would be a "typical" factory humidity and Case 2 would be high humidity day. At the temperature which Case 2 reinitiated void growth, the system is gelling. As the temperature increases the moisture concentration in the resin phase of Case $1, C(\infty)$, drops below C(sat) but the resin viscosity/gell structure will not allow bubble collapse.

In the bubble growth summary $c(\bar{\infty})$ is interpreted as the effective average moisture concentration in the laminate prior to gellation since

$$
c(\infty a t)=c(\infty \text {, initial })-c(\infty \text {, desorption })-c(\infty \text {, bubble transport/evaporation })
$$

The desorption process under vacuum has been described previously. The bubble/evaporation process would involve bubble transport to the laminate edge or upper surface where the bubbles burst and release their vapors, Equation (33). Using Gent's finding (Ref 27) for the interpretation of the effective "pour" size implied by the permeability coefficients for a porous solid in the previous section, bubbles of about $0.03 \mathrm{~cm}$ can migrate vertically and of about 0.7 to $1 \mathrm{~cm}$ in the plan of, or between the plies. The relative transport of bubbles will correspond to the relative resin volumetric flows in the three orthognal directions. Apportionment of bubble transport with resin transport, previous section, suggests the

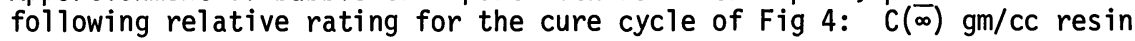

$\begin{array}{cll}\text { No of Plies } & \frac{0.0054}{\text { good }} & \frac{0.022}{10} \\ 100 & \text { borderline } & \text { borderline } \\ 400 & \text { porosity } & \text { porosity }\end{array}$

A visual examination of these cured laminates will show a concentration of porosity (many small bubbles) and/or large bubbles/voids on the interlaminer planes. This is because bubbles below about $0.03 \mathrm{~cm}$ in diameter can rise through the fiber mass within a ply but when they reach 0.1 to $1 \mathrm{~cm}$ in diameter they are blocked from vertical motion. This size discrimination is inherent in the flow concept within Darcy's Law (Ref 27 \& 31) and the directional dependence of the permeability for layered systems. 
Some interesting observations are:

1. The vacuum part of the cycle always has the potential of creating large voids.

2. The initial moisture content of the prepreg is very important. A prepreg equilibrated at $50 \%$ to $60 \% \mathrm{RH}$ will have a maximum residual bubble size of 0.38 to $0.50 \mathrm{~cm}$ and no potential for further growth when heated under pressure, whereas a prepreg equilibrated at $90 \%$ to $100 \% \mathrm{RH}$ has a maximum residual bubble size of 2.6 to $3.5 \mathrm{~cm}$ and a potential for further growth during the heating under pressure.

3. The approach utilized in the above calculations is approximate, but it does account for the effect of the moving bubble-resin boundary on the concentration profile and diffusion.

4. If the prepreg is equilibrated with moisture at a relative humidity, $(\mathrm{RH})_{0}$, then in order to prevent the potential for void growth by diffusion at all times when the temperature during the curing cycle is $T(t)$, the pressure at all points of the prepreg $P(t)$ must satisfy the following inequality:

$$
P \geqq 4.962 \times 10^{3} e^{-4892 / T} \quad(R H)_{0}
$$

where $(\mathrm{RH})_{0} \%$ - the relative humidity to which the prepreg was exposed

$P(a t m)$ - the resin pressure in the prepreg at various times.

The equation was derived from the requirement that void growth by diffusion cannot occur if $\mathrm{C}_{\text {sat }}>\mathrm{C}_{\infty}$.

5. The resin pressure varies throughout the curing slab, from the upper surface when it is at the vacuum pressure, to the tool surface and from the slab center to the lateral edges where the pressure is again the vacuum pressure. The resin gradient, in Fig 4 , will also be the resin pressure gradient as the resin pressure is lost as the resin flows through the porous structure.

6. Alternative approaches to curing pressurization would suppress void generation. Another alternative is to control the factory work environment, as it is usually implemented in adhesive bonding activities.

Returning again to Fig 1, we note that the cured laminate characteristics are in principle defined in both a physical chemistry and a structural quality sense. Perspectives of some of these topics are to be found in contributions of Halpin, and Chu and Seferis in Ref 38. In the contribution by Halpin the impact of usage environmental history through moisture absorption and the subsequent depression of the resin glass transition temperature are addressed to define the usage limits of cured laminates ( $\mathrm{Tg} \sim 177$ to $190^{\circ} \mathrm{C}$ cured to 135 $120^{\circ} \mathrm{C}$ (in service). Thermal excursions above the in-service Tg create the potential for cavitation induced by the superheated absorbed water vapor in a process similar to that studied in Ref 32 . Equation (28) states the criteria for this process as

$$
P(\text { int }) \simeq 2.5 G(t, T)
$$

where $P$ (int) is the internal superheated moisture pressure in the voids, Equations (30)-(33), and $G(t, T)$ is effective shear modulus of the elastomeric ( $T>\operatorname{Tg}($ resin) epoxy network. It is this physical process which was described experimentally in Ref 38 .

\section{SUMMARY}

Through the illustrations, which were specific to a topical class of prepreg systems, it has been demonstrated that limiting concepts of the fundamental processes do capture the essence of the life cycle issues. The model developed describes the prepreg through curing in terms of basic polymerization, polymer mechanics and transport processes. Internal temperature distribution, viscosity, degree of cure, resin flow, volatiles and the occurrence of voids/ porosity have been addressed as a function of factory history/facility control, and position and time during cure. The systems approach lay the basis for systematic trades and optimization between resin chemistry, factory operations and cure procedures. Dominant material parameters have been identified but future data development is required. The interested reader is also referred to the work of Macosko and Coworkers (Refs 18, 25 \& 38) for similar activities in the treatment of rapidly reacting systems. The authors recognize that the specific analysis illustrated will benefit from additional work and hopes that this contribution will stimulate the maturing of this area.

Acknowledgement - The authors gratefully acknowledge the partial support of this work by the Polymer Program, Materials Division, National Science Foundation under Grant No DMR-820-1228. 


\section{REFERENCES}

1. P.R. Guvett and A.W. Cardrick, "The Certification of Composite Airframe Structures", Aeronautical Journal, July 1980 (188-203).

2. J.D. Keenan, J.C. Seferis and J.T. Quin1ivan, J. App1 Polymer Sci, 24, 2375 (1979).

3. H.S. Chu and J.C. Seferis, "The Role of the Polymeric Matrix on the Processing and Properties of Composite Materials", J.C. Seferis and L. Nicolais, Eds., Plenum Press (1983).

4. J.J. Harris and S.C. Temin, J. App1 Polymer Sci, 10, 523 (1966).

5. H. Lee and K. Melville, Handbook of Epoxy Resins, McGraw-Hi11, New York (1967).

6. W.G. Potter, Epoxide Resins, Springer-Verlag, New York (1970).

7. A. Apicella, L. Nicolais, C. Carfagna, C. deNotaristefani and C. Voto, National SAMPE Exhibit (Proc), 27, 753 (1982).

8. A. Apicella, L. Nicolais and J.C. Halpin, National SAMPE Exhibit (Proc), (1983).

9. P.J. Flory, "Principles of Polymer Chemistry", Cornell Univ Press, Ithaca, 1953.

10. P.J. Flory, "Condensations Polymerization and Constitution of Condensations Polymers", in R.E. Burk and 0. Grummitt, Eds., High Molecular Weight Organic Compounds (Frontiers in Chemistry, Vo1 6), Interscience Pub, New York, 1949; see aíso P.J. Flory, Chem Revs, 39, 137 (1946).

11. M.A. Kama1, Polymer Engineering Science, 14, 231-239 (1974); M.R. Kama1 and S. Sourour, Polym Engrg Sci, 13, 59-64 (1973).

12. M.B. Roller, Polymer Engineering Science, 15, 406-414 (1975).

13. P.J. Flory, J. Am Chem Soc, 62, 1057 (1940).

14. T.G. Fox, S. Gratch and S. Loshack, "Viscosity Relationships for Polymers in Bulk and in Concentrated Solutions", Chapter 12 in F.R. Eirick, Ed., Rheology, Academic Press, New York, Vo1 1 (1956).

15. F. Bueche, "Physical Properties of Polymers", Interscience Publishers, New York (1962).

16. J.D. Ferry, R.F. Landel and M.L. Williams, J App1 Phys, 26, 359.(1955).

17. D.H. Kaelble, data by personal communication (1975); see also "Rheology of Polymers Used as Adhesives" in Treatise on Adhesion and Adhesives, Vol 1, Ed by R.L. Patrick, Marcel1 Dikher Inc., New York (1967).

18. C.W. Macosko and D.R. Miller, Macromolecules, 9 , 199 to 206, (1976); E.M. Valles and C.W. Macosko, Macromolecules, 12, 521-526 (1979).

19. A.C. Loos and G.S. Springer, "Calculation of Cure Process Variables During Cure of Graphite - Epoxy Composites" in Producibility and Quality Assurance of Composite Materials, ASTM STP, 1983 (in print).

20. J.M. McKelvey, Polymer Processing, J. Wiley Sons, New York, 1962.

21. T.E. Stonecypher, E.L. Allen, D.E. Mastin, and D.A. Willoughby, "Special Problems in Curing Highly Exothermic Propellents", Chem Eng Progr Symposium Series, 62, 7 (1966).

22. S.D. Gehman, "Heat Transfer in Processing and Use of Rubber" in Rubber Reviews: Rubber Chemistry and Technology, ACS, 40, 36-9.9 (1967).

23. D.A. Hills, "Heat Transfer and Vulcanizations of Rubber", Chap 5, Elsevier, London, Eng (1971).

24. R.C. Progelhof and J.L. Throne, Polym Eng and Sci, 15, 690-695 (1975).

25. E. Broyer and C.W. Macosko, Alche Journal, 22, 268-276 (1976).

26. H.S. Carslaw and J.C. Jaeger, Conduction of Heat in Solids, Oxford, 2nd ed (1959).

27. A.N. Gent and K.C. Rusch, J. Cellular P1ast, Jan, 46-51 (1966).

28. P.C. Carman, Flow of Gases Through Porous Media, Academic Press Inc, New York (1957).

29. A.E. Scheidegger, The Physics of Flow Through Porous Media, MacMillan Co, New York (1957).

30. P. Forrchheimer, Zeitschr. Vereinies Deutsch. Ing. 45, 1781-1788 (1901).

31. J. Kozeny, Akad. Wiss. Wein. Ber., 136, 2A, 271-306 (1927).

32. A.N. Gent and D.A. Tompkins, J.App1 Phys, 40, 2520-2525 (1969); R.L. Dinecour and A.N. Gent, J. Polym Sci, A-2,, 1853 (1967).

33. D.H. Kaelble, Trans Soc Rheol, 15, 275-296 (1971).

34. A.N. Gent and P.B. Lind1y, Proc. Roy. Soc. (London), A249, 195 (1958), A.N. Gent and D.A. Tompkins, J. Polym Sci, Part A-2,1, 1483-1488 (1969).

35. Scriven, $\mathrm{X}$, Chem Engrg Sci, 10, 1 (1959).

36. Weinberg and Subramanian, Preprints AICHE, Chicago Meeting, Nov (1980).

37. "The Role of the Polymeric Matrix on the Processing and Properties of Composite Materials", L. Nicolais and J.C. Seferis, Eds, Plenum Press (1983).

38. E.L. McKagu1 et a1., J. Comp Mat, $\underline{9}, 2$ (1975). 